\title{
OSTEONECROSIS WITH THE USE OF POLYMETHYLMETHACRYLATE CEMENT FOR HIP REPLACEMENT: THERMAL-INDUCED DAMAGE EVIDENCED IN VIVO BY DECREASED OSTEOCYTE VIABILITY
}

\author{
M.R. Whitehouse ${ }^{1,2, *}$, N.S. Atwal ${ }^{1,3}$, M. Pabbruwe ${ }^{1}$, A.W. Blom ${ }^{1,2, \S}$ and G.C. Bannister ${ }^{1,2, \S}$ \\ ${ }^{1}$ Department of Orthopaedic Surgery, Musculoskeletal Research Unit, University of Bristol, Bristol, UK \\ ${ }^{2}$ Avon Orthopaedic Centre, Southmead Hospital, Bristol, UK \\ ${ }^{3}$ Department of Trauma and Orthopaedics, Bristol Royal Infirmary, Bristol, UK
}

\begin{abstract}
Thermal damage to host bone is a possible source of compromise of fixation in patients undergoing cemented total hip replacement (THR). Data on the subject to date are derived from mathematical modelling powered by animal studies. The aim of this study was to assess the effect of cement thickness on osteocyte viability in a population of patients undergoing cemented THR.

An in vivo model was designed and validated by means of a finite element analysis. During standard hip joint replacement in 14 patients, the femoral necks were exposed before final resection to the heat of a curing cement mantle equivalent to 2.5 (Group 1) or $5 \mathrm{~mm}$ (Group 2) in vivo in the cemented acetabulum. Matched controls were collected for each patient. Osteocyte counts and viability were assessed by means of haematoxylin and eosin (H\&E) stain and lactate dehydrogenase (LDH) assay. Ex vivo experiments were performed to determine the extent of thermal insult.

$\mathrm{H} \& \mathrm{E}$ staining proved unreliable for assessing thermal insult in the short term. The LDH assay was reliable and demonstrated a significant reduction in osteocyte viability to a depth of $2.19 \mathrm{~mm}$ in group 1 and $9.19 \mathrm{~mm}$ in group 2 . There was a significant difference between the groups at all depths. The ex vivo experiments revealed thermoclines indicating that host bone in the population undergoing cemented THR is more sensitive to the thermal insult delivered by curing polymethylmethacrylate cement than previously believed.

This thermal insult may weaken the fixation between bone and cement and contribute towards aseptic loosening, the commonest cause of failure of THRs.
\end{abstract}

Keywords: Hip-arthroplasty; PMMA-bone cement; ex vivo polymerisation heat; in vivo thermal trauma; osteocyte necrosis.

*Address for correspondence

Michael Richard Whitehouse

Musculoskeletal Research Unit

Avon Orthopaedic Centre (Lower Level)

Southmead Hospital, Westbury-on-Trym,

Bristol, BS10 5NB, UK

Telephone Number: 01173232291

FAX Number: 01173235936

E-mail michael.whitehouse@bristol.ac.uk
Introduction

Total hip replacement is a well established procedure for treatment of degenerative disorders of the hip (Goldberg et al., 2011) with high patient satisfaction (Mahomed et al., 2011). It is a cost effective surgical intervention (Räsänen et al., 2007) and potentially cost saving over the life of the patient (Chang et al., 1996).

Hip prosthesis can be fixed to bone using polymethylmethacrylate bone cement pioneered by Sir John Charnley (Charnley, 1960) or by uncemented means. The proportion of total hip replacements utilising each type of fixation varies by region (Berry and Bozic, 2010; Hailer et al., 2010). Registry data indicates that the survivorship of cemented is superior to uncemented devices in the medium and long-term (Hailer et al., 2010; NJR, 2011).

The commonest cause of failure of total hip arthroplasty is aseptic loosening, which is a progressive failure of the fixation between bone and cement. In the NJR report for the period 2009-2010, aseptic loosening accounted for $49 \%$ of the total revision burden in total hip arthroplasty (NJR, 2011).

The polymerisation of PMMA bone cement that occurs during the curing process is an exothermic reaction, releasing $52 \mathrm{~kJ}(13 \mathrm{kcal})$ per mole of methylmethacrylate (MMA) (Kühn, 2000). This results in heat production of approximately 1.4 to $1.7 \times 10^{8} \mathrm{~J} / \mathrm{m}^{3}$. The heat produced is a potential cause of osteonecrosis; the potential for thermal injury is greater on the acetabular side as the area is more contained with less heat loss by radiation, does not have the beneficial heat sink effect of the metal stem; and the polyethylene acetabular component acts as an insulator. Fixation of the cemented hip joint components is reliant on the macrolock and microlock of the cement mantle with bone structures, which acts as a grout rather than an adhesive. The macrolock can be improved by the use of keyholes (Mburu et al., 1999). Microlock is reliant on the creation of a porous dry bed to receive the cement and effective pressurisation of the cement during its working phase (Askew et al., 1983; Flivik, 2005). Thermal osteonecrosis and the resulting host bone remodelling may lead to loss of the microlock created and loosening of the prosthesis at the cement-bone interface (Berman et al., 1984).

Previous investigations of the effect of curing heat on cemented joints either address the femoral side only (Toksvig-Larsen et al., 1991), rely on laboratory models (DiPisa et al., 1976; Sih et al., 1980; Leeson and Lippitt, 1993; Revie et al., 1994) or utilise animal models or 
models based on animal experiment data (Moritz and Henriques, 1947; Slooff, 1971; Lundskog, 1972; Linder, 1977; Eriksson and Albrektsson, 1983; Berman et al., 1984; Eriksson et al., 1984; Santin et al., 2004; Quarini et al., 2006). The effect on bone viability, as indicated by living osteocytes, of curing PMMA cement in the aged human population undergoing cemented total hip replacement has not been investigated.

The aim of this study was to assess the effect of cement mantle thickness on osteocyte viability in a population of patients undergoing cemented total hip replacement. We hypothesised that the exothermic reaction of the curing PMMA would result in the conduction of heat in exposed bone leading to the temperature threshold for osteocyte death being reached or exceeded. Our hypotheses were that the depth of cement mantle would influence the proportion of viable osteocytes following exposure to the heat produced by cement mantles of 2.5 and $5 \mathrm{~mm}$ and that there would be a significant difference in the osteocyte counts or viability observed by nuclear staining with haematoxylin (H\&E stain), or by the lactate dehydrogenase (LDH) assay, respectively.

\section{Materials and Methods}

\section{Sample selection}

Sequential patients undergoing cemented total hip replacement under the care of the senior author were identified and approached at their pre-operative assessment by the first author. Inclusion criteria were patients undergoing cemented total hip replacement for a diagnosis of advanced osteoarthritis. Exclusion criteria were previous surgery to the ipsilateral hip, using a different cement type or brand, femoral neck fracture, a clinical and radiological diagnosis of avascular necrosis (ischaemic osteonecrosis), rheumatoid arthritis, septic arthritis or other inflammatory arthropathies of the hip. No pilot data were available for this study therefore group sizes were estimated at $n=7$ in each group, which is consistent with similar histochemical studies where large volumes of results are obtained from each specimen. The proportion of male:female patients in the groups was not significantly different (Group 1, 3:4; Group $2,1: 6 ; p=0.56$ ). The age ranges were normally distributed and there was no significant difference between the groups (Group 1 mean 70 years (SD 3.9); Group 2 mean 75 years (SD 5.3); $p=0.078$ ) (Table 1). A post hoc power analysis on the basis of the group 1 sample and control data revealed that for an $\alpha$ error probability of 0.05 and the given sample sizes a power of $>0.99$ had been achieved $(\beta<0.01)$. Ethical approval was sought from and granted by the local Research Ethics Committee prior to commencement of the study (ref: 06/Q2002/106). Patients signed a consent form before participation in the study.

\section{Sample collection}

An in vivo model was designed, such that a section of redundant femoral neck (femoral neck that is discarded routinely as part of the hip replacement procedure) could be exposed to curing PMMA cement (Palacos $R+G$, Heraeus Medical, Wehrheim, Germany; our standard PMMA
Table 1: Patient demographics.

\begin{tabular}{|c|c|c|c|c|c|}
\hline Group & $\begin{array}{c}\text { Depth of } \\
\text { Cement }\end{array}$ & $\begin{array}{c}\text { Mean } \\
\text { Age (SD) }\end{array}$ & $\boldsymbol{n}$ & Male : Female & Left : Right \\
\hline $\mathbf{1}$ & $5 \mathrm{~mm}$ & $\begin{array}{c}69.7 \\
(3.9)\end{array}$ & 7 & $3: 4$ & $4: 3$ \\
\hline $\mathbf{2}$ & $7 \mathrm{~mm}$ & $\begin{array}{c}75.7 \\
(5.3)\end{array}$ & 7 & $1: 6$ & $2: 5$ \\
\hline
\end{tabular}

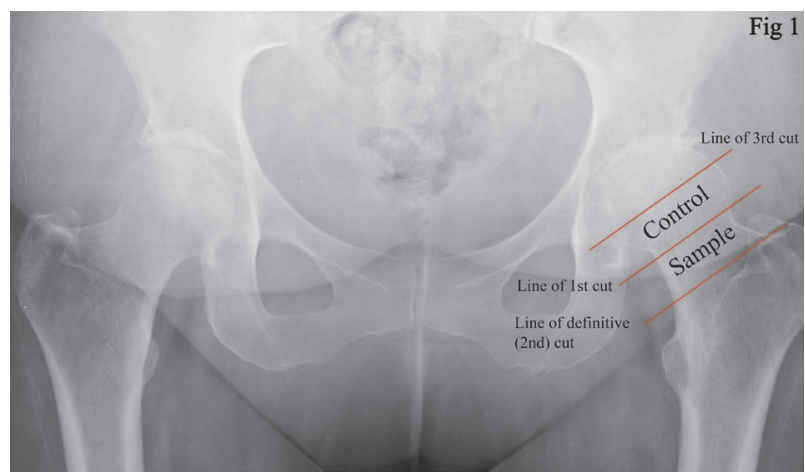

Fig. 1. Illustration of the femoral neck cuts and sampling performed in the in vivo model for exposure of bone to curing PMMA cement on an anteroposterior radiograph of the hips.

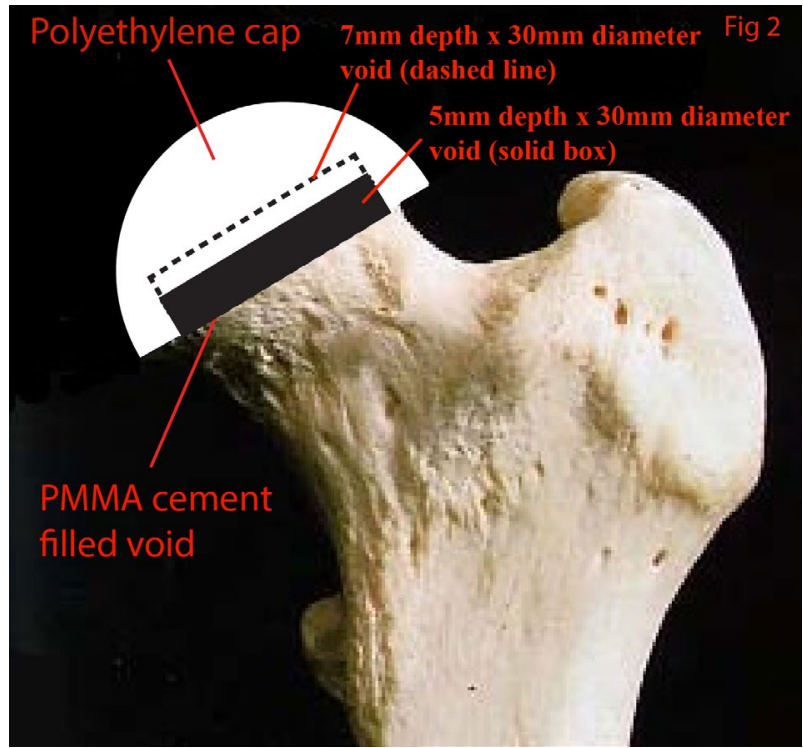

Fig. 2. Illustration of the application of the polyethylene cap to the prepared femoral neck performed in the in vivo model.

cement) of a known depth, contained within a polyethylene cap, during the total hip replacement procedure (Fig. 1 and 2 ). We used a polyethylene cap to reproduce the insulation of the bone by the thick layer of polyethylene used in cementing the acetabular component. The model was designed such that the experiment could be conducted in vivo then the bone subsequently harvested for histological and histochemical examination without impacting upon the performance of the total hip replacement. To achieve this, the femoral neck was initially cut long (at the headneck junction) leaving a redundant segment of femoral neck still in situ. After the acetabular preparation and insertion had been performed, a polyethylene cap with 
either a $5 \mathrm{~mm}$ (Group 1) or $7 \mathrm{~mm}$ (Group 2) deep central void filled with PMMA cement was then pressurised onto the cut surface of the femoral neck and held in place by a large pointed reduction forceps. Following curing of the cement, the segment of femoral neck was then harvested with the cap still attached at the level of the standard femoral neck osteotomy so that the arthroplasty could be performed as usual. The cement was allowed to cure for 10 minutes, whilst the cement in the acetabulum was also curing. Curing of the cement was confirmed by the operating surgeon by testing resistance to indentation as is standard surgical practice. All procedures were performed according to the standard technique of the senior author through a posterior approach (Bannister, 2003). Procedures were performed in parallel with the total hip replacement. The cap was then removed and the femoral neck sectioned into three segments. The neck was first divided into an anterior and posterior half to reduce cranial/caudal variation between specimens and then the anterior half was further divided into two equal sized samples. A specimen of matching thickness was taken from the exposed distal surface of the femoral head to act as a matched control that had not been exposed to PMMA. The two anterior segments of each were prepared with the LDH assay and the posterior segment with H\&E staining.

The validity of the in vivo model was independently confirmed by finite element analysis conducted independently of the research group (Worley Parsons Europe, Gloucester, UK; project number 251/13298). The thermal exposure generated in the study was modelled against that achieved in vivo on the acetabular side of a cemented total hip replacement. The model was performed in order to account for the geometry in vivo in addition to the thermal conductivity of the polyethylene and the bone. The equation governing the cement polymerisation and parameters used in the model were as described by Quarini et al. (2006). The model revealed that in order to create the equivalent thermal insult of a $2.5 \mathrm{~mm}$ and a $5 \mathrm{~mm}$ mantle in vivo on the acetabular side, cement thicknesses of $5 \mathrm{~mm}$ and $7 \mathrm{~mm}$ respectively would need to be used in our model.

The allocation of patients to the groups was blinded. A polyethylene cap, double wrapped in opaque wrappers was selected at random. Following collection of the samples (study group and controls) the depth of the cavity was confirmed with the use of a digital Vernier gauge. This depth was recorded along with anonymised patient demographic details.

\section{Histochemical and histological analysis}

Each specimen was analysed histochemically with a lactate dehydrogenase (LDH) assay to demonstrate bone viability according to the method of Wong et al. (1982) as developed by Stoddart et al. (2006) and histologically to perform osteocyte cell counts with haematoxylin and eosin (H\&E) staining according to the method of Humphreys et al. (1989). The LDH assay was chosen as according to the work of Stoddart et al. (2006) it achieves good penetration of the reagents into the specimens, avoids problems with interpretation due to autofluorescence of the bone and allows excellent viability determination. The enzymecytochemical stain used indicates LDH activity in viable cells, positively dark blue stained cells then contrast with the autofluorescence of bone when viewed by fluorescence microscopy.

\section{LDH assay}

After harvesting, the portions of the femoral neck assigned to the LDH-assay were immediately incubated in fresh medium at $37^{\circ} \mathrm{C}$. They were then washed in cooled $\left(4{ }^{\circ} \mathrm{C}\right)$ Hank's Balanced Salt Solution (HBBS) for two cycles of $10 \mathrm{~min}$ duration. A final wash for $30 \mathrm{~min}$ in $10 \mathrm{~mL}$ of HBBS containing 100,000 IU Penicillin/Streptomycin and $150 \mathrm{mg}$ Gentamicin per litre was performed. Sectioning of the samples using an annular saw with irrigation with cooled $\left(4^{\circ} \mathrm{C}\right) 0.9 \%$ sodium chloride $(\mathrm{NaCl})$ was performed to produce sections of $250 \mu \mathrm{m}$ thickness. The samples were then transferred to fresh medium and cultured at $37^{\circ} \mathrm{C}$ for three days. A base solution (5\% Polypep $+2 \mathrm{mM}$ glycine-glycine (gly-gly) $+0.75 \%$ sodium chloride $(\mathrm{NaCl})$ $(\mathrm{pH}=8.0))$ was prepared and stored at $4{ }^{\circ} \mathrm{C}$. The $\mathrm{LDH}$ solution was then prepared fresh on the day of the assay by adding $60 \mathrm{mM}$ lactic acid $+17.5 \mathrm{mg} \beta$-nicotinamide adenine dinucleotide (NAD) to make up $10 \mathrm{~mL}$ polypep base solution. The $\mathrm{pH}$ of the $\mathrm{LDH}$ solution was adjusted to 8.0 with $5 \mathrm{M} \mathrm{NaOH}$ and $30 \mathrm{mg}$ of Nitroblue Tetrazolium was added immediately prior to use. A small volume of the LDH solution (enough to cover the bone surface of each section) was added and the sample placed in a humidifier chamber covered with paraffin at $37^{\circ} \mathrm{C}$ for $4 \mathrm{~h}$ in the dark. For the actual LDH staining, the bone sections were preincubated in tissue culture medium containing $1 \mu \mathrm{g} / \mathrm{mL}$ ethidium homodimer for $10 \mathrm{~min}$ at $37^{\circ} \mathrm{C}$ in the dark. The sections were then washed with PBS before transferred to the LDH solution, which was prepared as described above. After four hours incubation in the LDH solution, the bone sections were washed in warm $\left(37^{\circ} \mathrm{C}\right) \mathrm{PBS}$ and fixed with $4 \%$ formalin buffered to $\mathrm{pH} 7.4$ at $4{ }^{\circ} \mathrm{C}$. The formalin fixed specimens were then evaluated unembedded by fluorescence microscopy.

\section{H\&E staining}

Specimens were fixed in cold $4 \%$ formalin solution for at least $48 \mathrm{~h}$. The slices were decalcified in a $30 \% \mathrm{v} / \mathrm{v}$ formic acid in $11 \% \mathrm{w} / \mathrm{v}$ citric acid solution for four days followed by $12 \% \mathrm{w} / \mathrm{v}$ EDTA solution $(12 \mathrm{mM})$ at $37^{\circ} \mathrm{C}$ for one week. The samples were cut to $4 \mathrm{~mm}$ thickness slices with an annular saw and then embedded in paraffin wax and multiple $4 \mu \mathrm{m}$ sections cut.

Viable osteocyte counts were performed using a Zeiss Axio Imager A1 (Carl Zeiss MicroImaging GmbH, Gottingen, Germany) connected to a standard desktop personal computer running QCapture Pro software (QCapture Pro, Ver. 5.1.1.14, QImaging, Surrey, Canada). Viable osteocyte counts were performed manually at x 100 magnification (ocular x10, objective x10). For fluorescence microscopy a Zeiss filter set \#10 (excitation BP 450$490 \mathrm{~nm}$, beam splitter FT $510 \mathrm{~nm}$, emission BP 515$565 \mathrm{~nm}$ ) was used with blue light illumination. The surface of the bone exposed to the PMMA cement was defined as depth $0 \mathrm{~mm}$. The field of interest was moved parallel to this surface until the entire width of the sample had been recorded. The depth of the field viewed was $0.875 \mathrm{~mm}$. 


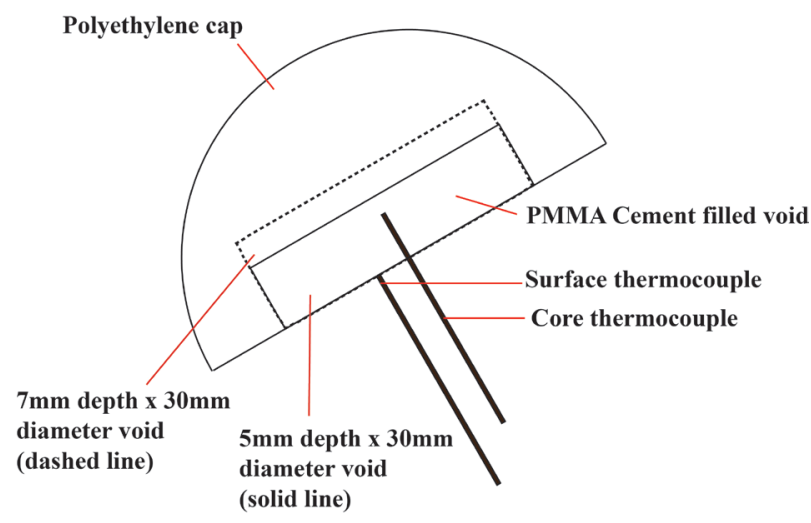

Fig. 3. In vitro model for the measurement of surface and core temperatures achieved during the PMMA cement curing.

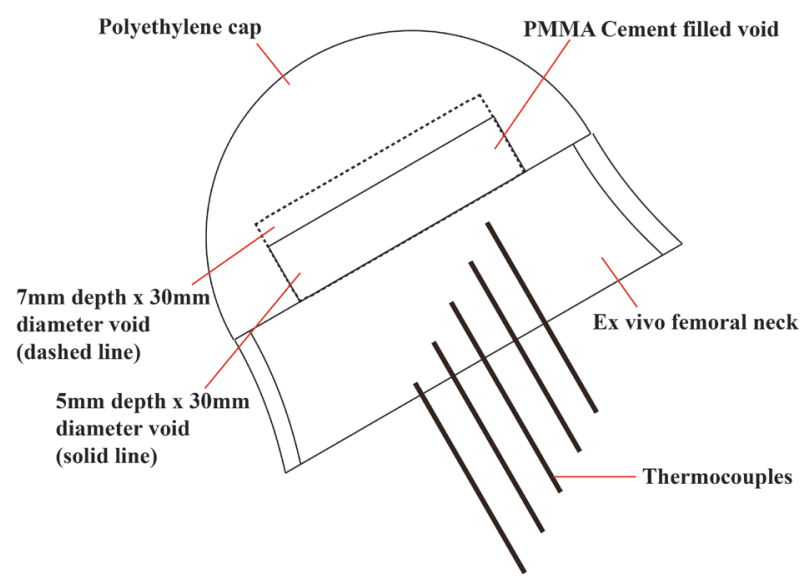

Fig. 4. Ex vivo model for the measurement of temperatures achieved at different depths of the PMMA cement during curing.
The field of interest was then moved perpendicular to the exposed surface until a new field of interest (depth 0.875 to $1.75 \mathrm{~mm}$ from the exposed surface) was viewed and again scrolled parallel to the exposed surface of bone until the entire width of the specimen had been captured. The fields of view parallel to the exposed surface were defined as rows. The average number of fields of view per row was 11 and the average number of rows was 12 per specimen, this gave an approximate area of $128 \mathrm{~mm}^{2}$ per specimen. For the LDH assay, the number of observed viable osteocytes in the cortical and cancellous bone areas was recorded and the number of lacunae not containing viable staining osteocytes counted. The contents of the vascular channels were excluded from the counts. For the H\&E stain, the number of lacunae containing stained osteocytes and the number of empty lacunae or lacunae containing only unstained material were counted. The counts were used to calculate the percentage of lacunae containing viable (LDH assay) or stained osteocytes (H\&E stain) in the defined field of interest.

\section{In vitro and ex vivo models}

The thermal insult achieved during the course of the experiments above was estimated by means of an in vitro and an ex vivo model. Both utilised the same polyethylene caps as used in the above experiments. In the first, the caps were placed with the aperture facing up and then the central void filled with Palacos $\mathrm{R}+\mathrm{G}$ cement flush with the face of the cap. Group 1 ( $5 \mathrm{~mm}$ void) and group 2 (7 mm void) were analysed. Thermocouples were mounted in a jig and set at an appropriate depth to record the surface temperature and the core temperature of the bolus of cement (Thermocouple type K light duty, Stock \# 342-8883, RS Components, Corby, Northants, UK) (Fig. 3). These were attached via a data logger (8 channel thermocouple temperature data logger, Stock \# 492-5105, Pico Technology Ltd, St Neots, Cambridgeshire, UK) to a standard laptop PC with a recording frequency of $2 \mathrm{~Hz}$. Temperature recordings were started 3 min after mixing commenced and continued until $19 \mathrm{~min}$. Ten runs were performed for each group. In the second experiment, redundant femoral necks were harvested from consenting volunteers undergoing total hip replacement in our unit, in the same fashion as the femoral necks in the main study. The age range was similar to the patients in the main study (mean age 71 years (SD 4.6). Thermocouples were mounted in the specimen at depths of 2, 4, 6, 8 and $10 \mathrm{~mm}$ from the exposed surface and fixed relative to the neck. Polyethylene caps prepared as above were then filled with cement and pressurised onto the exposed surface of the femoral neck (Fig. 4). The rest of the experiment was conducted as described above.

\section{Statistical analysis}

Statistical comparisons were performed in GraphPad InStat (GraphPad Software, La Jolla, CA, USA). The groups were compared using a Kolmogorov-Smirnov test to determine if they were normally distributed. Comparisons between groups were performed with a Mann-Whitney test when the data were not normally distributed. Where the data were normally distributed, two-tailed $t$ tests were performed; the test was paired or unpaired according to the data. Where proportions were compared, Fisher's exact test was used. Correlation was calculated with a Pearson correlation coefficient $(r)$. Significance was determined if $p<0.05$.

\section{Results}

\section{LDH assay}

The mean counts of osteocyte viability at all investigated depths of the sample expressed as a percentage are given in Table $2(100=$ all osteocytes viable, $0=$ no osteocytes viable). The observed viability was lower in the sample groups when compared to their controls (group 1 (5 mm) c.f. controls $p<0.0001$; group $2(7 \mathrm{~mm})$ c.f. controls $p<0.0001$ ) and in the thicker cement mantles (group 2 ) when compared to the thinner mantles (group 1) $p=0.0002$.

Comparisons of the observed viabilities of the group $1(5 \mathrm{~mm})$ and group $2(7 \mathrm{~mm})$ samples and the samples and their matched controls at different depths are shown in Figs. 5 to 7. There was a significant difference observed between the group 1 and 2 samples at all individual 
Table 2: Mean \% of viable osteocytes; LDH assay.

\begin{tabular}{|c|c|c|c|}
\hline & Mean & SD & Range \\
\hline Group 1 Samples (5 mm mantle) & 37.9 & 2.6 & $32.2-41.2$ \\
\hline Group 1 Controls & 45.3 & 1.1 & $43.4-46.9$ \\
\hline Group 2 Samples (7 mm mantle) & 24.5 & 8.5 & $17.7-52.3$ \\
\hline Group 2 Controls & 45.5 & 6.8 & $37.6-66.1$ \\
\hline
\end{tabular}

Table 4: Recorded temperatures at the surface and core of group 1 and 2 in vitro and time in seconds (s) in excess of temperature thresholds.

\begin{tabular}{|c|c|c|c|c|}
\hline & $\begin{array}{c}\text { Group 1 } \\
\text { (surface) }\end{array}$ & $\begin{array}{c}\text { Group 1 } \\
\text { (core) }\end{array}$ & $\begin{array}{c}\text { Group 2 } \\
\text { (surface) }\end{array}$ & $\begin{array}{c}\text { Group 2 } \\
\text { (core) }\end{array}$ \\
\hline Mean $\left({ }^{\circ} \mathbf{C}\right)$ & 27.0 & 32.8 & 30.9 & 42.2 \\
\hline Max $\left({ }^{\circ} \mathbf{C}\right)$ & 34.8 & 54.0 & 45.6 & 76.8 \\
\hline Min $\left({ }^{\circ} \mathbf{C}\right)$ & 22.6 & 22.8 & 23.2 & 24.4 \\
\hline$>\mathbf{4 7}^{\circ} \mathbf{C}(\mathbf{s})$ & 0 & 112 & 0 & 310 \\
\hline$>\mathbf{5 0}{ }^{\circ} \mathbf{C}(\mathbf{s})$ & 0 & 75 & 0 & 263 \\
\hline $\mathbf{> 5 5}^{\circ} \mathbf{C}(\mathbf{s})$ & 0 & 0 & 0 & 202.5 \\
\hline $\mathbf{7 7 0}^{\circ} \mathbf{C}(\mathbf{s})$ & 0 & 0 & 0 & 80 \\
\hline
\end{tabular}

Table 3: Mean \% of viable osteocytes; H\&E stain.

\begin{tabular}{|c|c|c|c|}
\hline & Mean & SD & Range \\
\hline Group 1 Samples (5 mm mantle) & 54.6 & 0.9 & $53.1-56.1$ \\
\hline Group 1 Controls & 55.3 & 1.0 & $53.6-56.6$ \\
\hline Group 2 Samples (7 mm mantle) & 54.0 & 0.6 & $53.0-55.2$ \\
\hline Group 2 Controls & 54.3 & 0.2 & $52.7-55.3$ \\
\hline
\end{tabular}

Table 5: Time in excess of temperature thresholds according to depth in ex vivo femoral neck for group 1 (5 mm mantle) and group 2 (7 mm mantle).

\begin{tabular}{|c|c|c|c|c|}
\hline \multirow{3}{*}{$\begin{array}{c}\text { Depth } \\
(\mathrm{mm})\end{array}$} & \multicolumn{4}{|c|}{ Time (s) in excess of temperature thresholds } \\
\hline & $>70^{\circ} \mathrm{C}$ & $>55{ }^{\circ} \mathrm{C}$ & $>50^{\circ} \mathrm{C}$ & $>47^{\circ} \mathrm{C}$ \\
\hline & Gp $1 /$ Gp 2 & Gp $1 /$ Gp 2 & Gp $1 /$ Gp 2 & $\mathrm{Gp} 1 / \mathrm{Gp} 2$ \\
\hline 2 & $0 / 11$ & $11 / 33$ & $26 / 97$ & $78 / 161$ \\
\hline 4 & $0 / 0$ & $0 / 0$ & $0 / 0$ & $0 / 0$ \\
\hline 6 & $0 / 0$ & $0 / 0$ & $0 / 0$ & $0 / 0$ \\
\hline 8 & $0 / 0$ & $0 / 0$ & $0 / 0$ & $0 / 0$ \\
\hline 10 & $0 / 0$ & $0 / 0$ & $0 / 0$ & $0 / 0$ \\
\hline
\end{tabular}

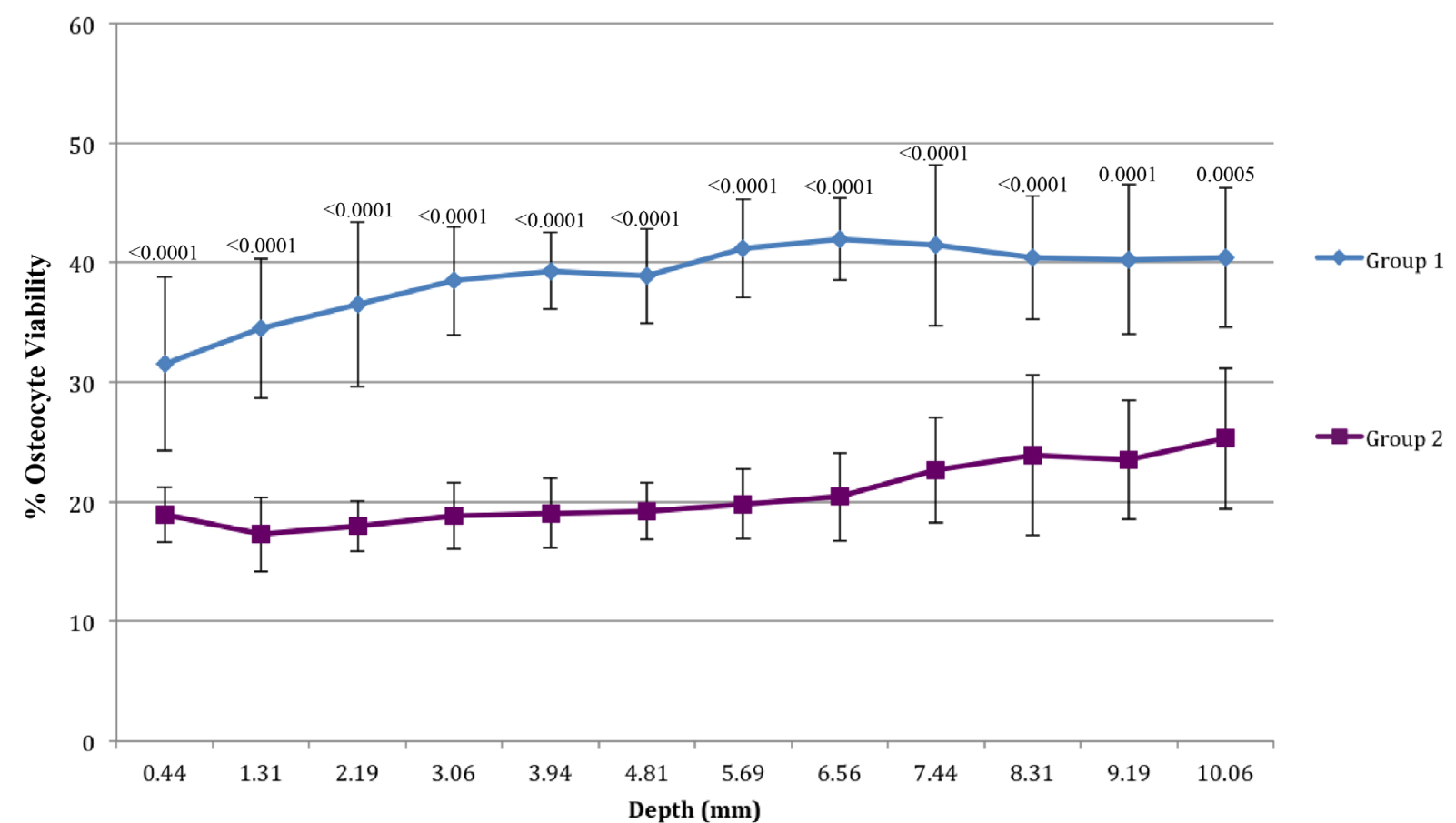

Fig. 5. Observed osteocyte viability (mean $\pm \mathrm{SD}$ ) for the LDH assay at different depths for group 1 (5 mm mantle) and group 2 (7 mm mantle) samples.

depths, between the group 1 samples and their matched controls to a depth of $2.19 \mathrm{~mm}$ and between the group 2 samples and their matched controls to a depth of $9.19 \mathrm{~mm}$. Fig. 8 demonstrates the LDH assay in a section of bone with a lacuna containing a viable osteocyte, a lacuna not containing a viable osteocyte and a vascular channel marked.

\section{H\&E counts}

The mean osteocyte counts determined by the H\&E stain as a proportion of occupied to unoccupied lacunae expressed as a percentage $(100=$ all osteocytes viable, $0=$ no osteocytes viable) are shown in Table 3.
There was no significant difference observed between the mean osteocyte counts of group $1(5 \mathrm{~mm})$ and group $2(7 \mathrm{~mm})$ samples $(p=0.220)$ or between the samples and their matched controls (group $1 p=0.114$, group 2 $p=0.240$ ). There were no significant differences observed between the samples and controls at each sample depth (Figs. 9 to 11). Fig. 12 demonstrates the H\&E stain in a section of bone with a lacuna containing an osteocyte, an empty lacuna and a vascular channel marked.

\section{LDH assay $c . f$. H\&E counts}

When the results of the LDH osteocyte viability assay and the H\&E counts were compared, a significant difference 


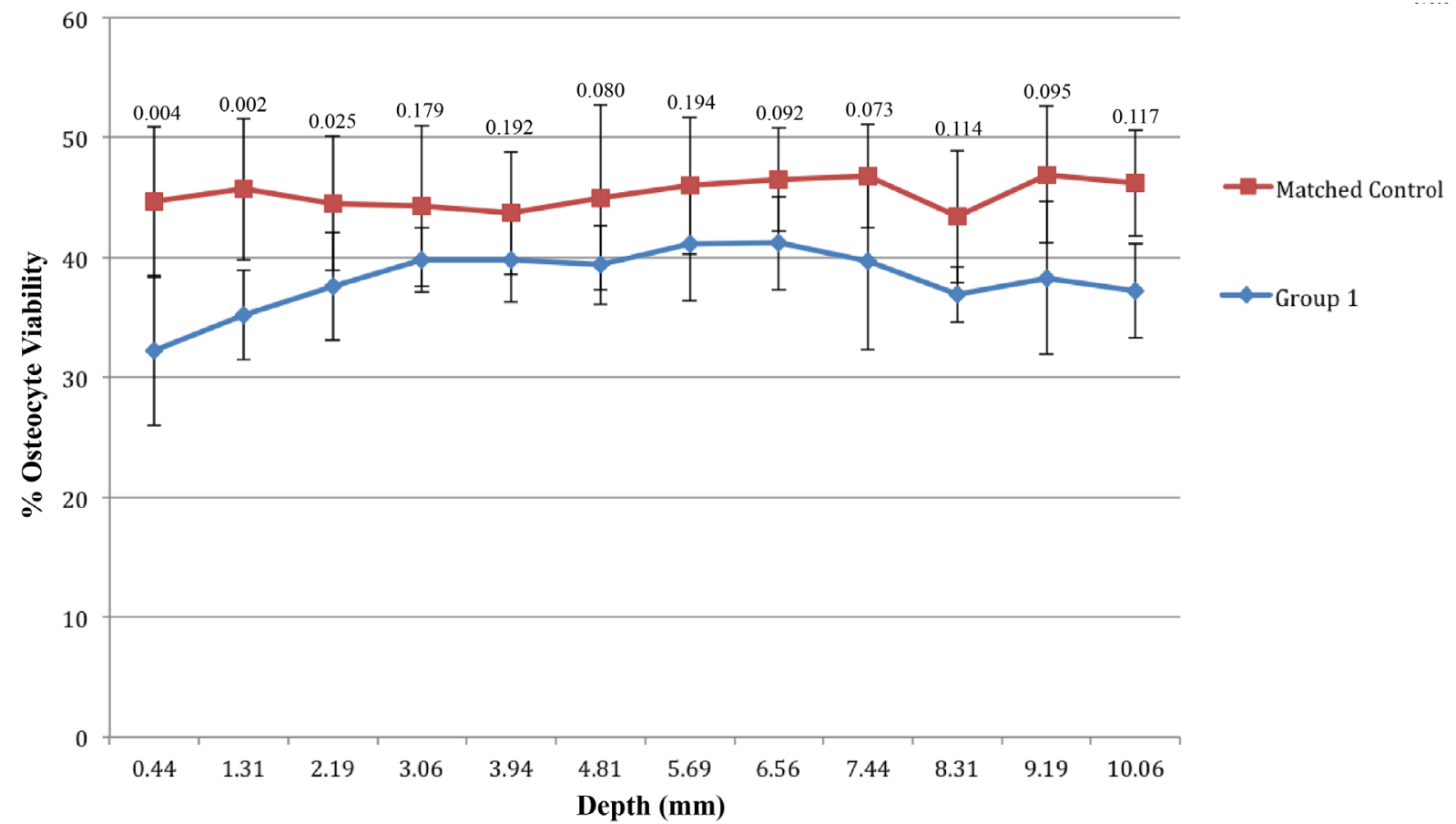

Fig. 6. Observed osteocyte viability (mean $\pm \mathrm{SD}$ ) for the LDH assay at different depths for group 1 (5 mm mantle) samples and their matched controls with $p$ values given above the data points.

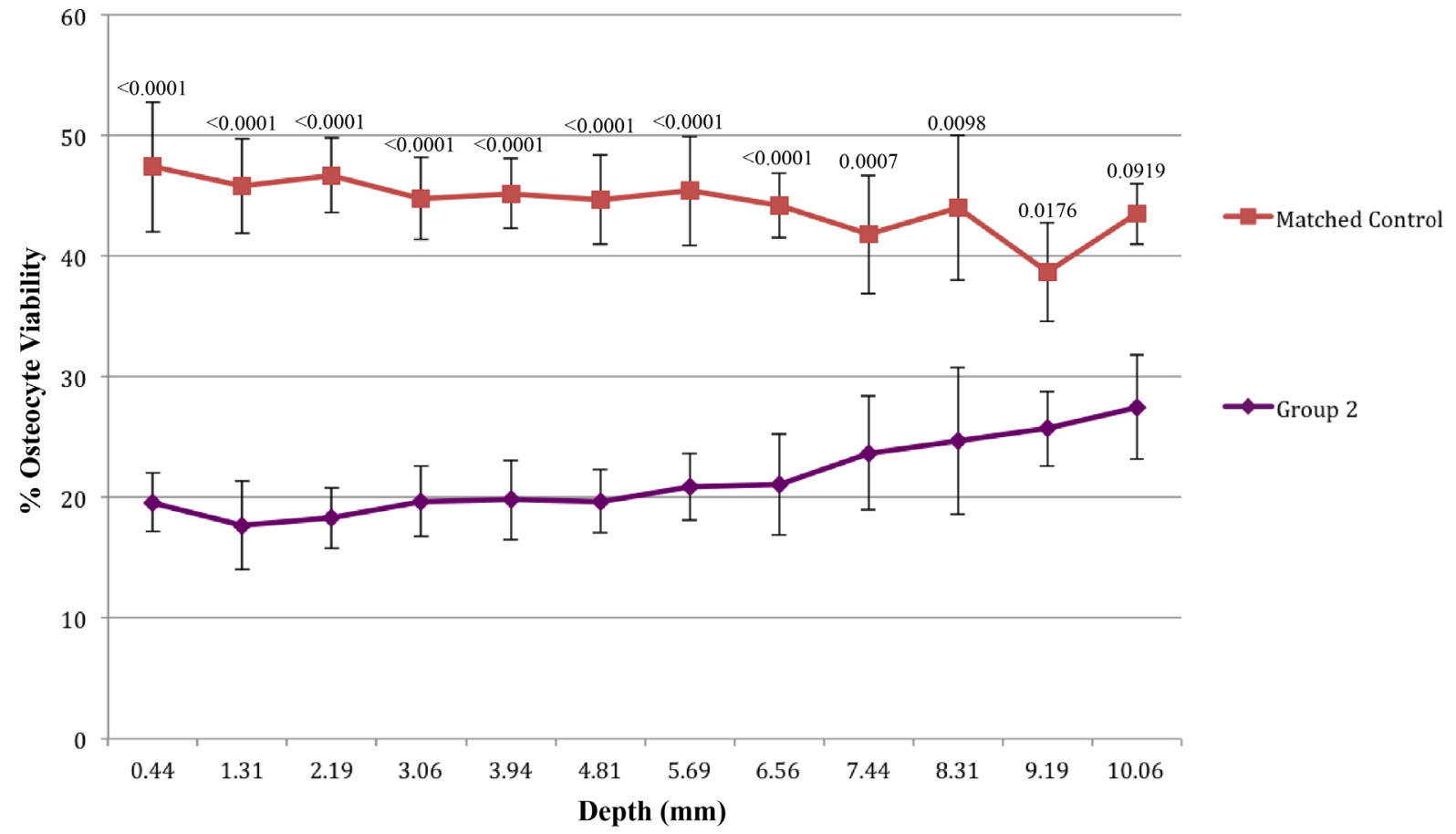

Fig. 7. Observed osteocyte viability (mean \pm SD) for the LDH assay at different depths for group 2 (7 mm mantle) samples and their matched controls with $p$ values given above the data points.

was observed at all depths in both the group $1(5 \mathrm{~mm} ; p$ values $<0.0001-0.0099)$ and group 2 (7 mm; $p$ values all $<0.0001$ ) samples (Figs. 13 and 14). In contrast to the H\&E stain, the LDH assay was able to discriminate between group 1 and group 2.

\section{Correlation}

Correlation was calculated for separate samples from the same specimens and between two observers. The correlation coefficients between the separate samples from the same specimens were 0.91 and 0.93 ; between two observers for two separate specimens, the coefficients were 0.84 and 0.93 . These results indicate excellent correlation.

\section{Measured temperatures}

The mean values of the measured surface and core temperatures for group $1(5 \mathrm{~mm})$ and $2(7 \mathrm{~mm})$ are shown in Fig. 15. Table 4 shows summary data including the time spent in excess of temperature thresholds identified in the literature as significant for damage to bone (see discussion). 
Fig. 8. LDH assay on bone section of a cortical bone area from group 1 ( $5 \mathrm{~mm}$ cement mantle thickness) at a depth of $0.875 \mathrm{~mm}$ from the surface exposed to curing PMMA cement. The white arrow demonstrates an empty lacuna and the black arrow a lacuna containing a viable osteocyte. A vascular channel is labelled with the letters VC. The exposed surface of bone is closest to the lower edge of the image (scale bar 0-100 $\mu \mathrm{m}$ ).
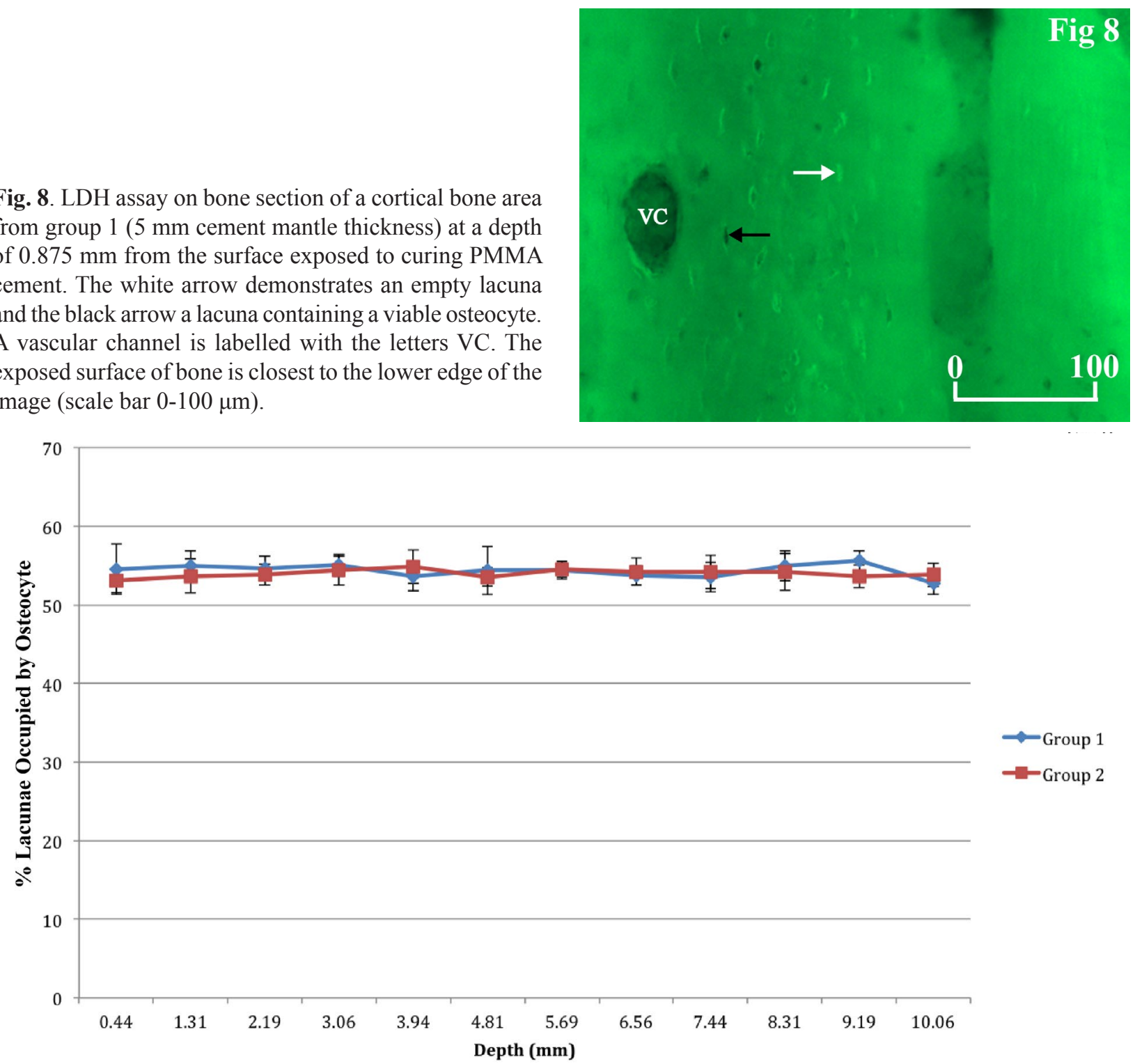

Fig. 9. Observed osteocyte counts (mean $\pm \mathrm{SD}$ ) for the H\&E stain at different depths for group $1(5 \mathrm{~mm}$ mantle) and group 2 (7 mm mantle) specimens and their matched controls.

No surface temperatures were recorded in excess of the temperature thresholds. Core temperatures in excess of all thresholds were identified in group 2 and in excess of $70{ }^{\circ} \mathrm{C}$ for $80 \mathrm{~s}$. The $50^{\circ} \mathrm{C}$ threshold was exceeded for $75 \mathrm{~s}$ in group 1 but the 55 and $70{ }^{\circ} \mathrm{C}$ thresholds were not exceeded.

The isotherms and duration in excess of the temperature thresholds identified from the literature (see discussion) for the group 1 (5 $\mathrm{mm})$ and group $2(7 \mathrm{~mm})$ ex vivo specimens are shown in Table 5. When the polyethylene caps were applied to the ex vivo specimens, the $55{ }^{\circ} \mathrm{C}$ threshold was exceeded at a depth of $2 \mathrm{~mm}$ in group 1 and the $70{ }^{\circ} \mathrm{C}$ threshold at a depth of $2 \mathrm{~mm}$ in group 2 .

\section{Discussion}

Satisfactory preparation and even staining of the samples was observed throughout the study. Decreased osteocyte viability was observed in samples compared to controls and in the cases with thicker cement mantles than thinner cement mantles.

A number of authors have identified thresholds for thermal damage to bone. These studies were conducted in animal models. Eriksson and Albrektsson found that a temperature in excess of $47^{\circ} \mathrm{C}$ sustained for more than 1 min impaired subsequent bone formation and that a temperature of $50{ }^{\circ} \mathrm{C}$ caused widespread bone tissue injury (Eriksson and Albrektsson, 1983). A temperature of $50^{\circ} \mathrm{C}$ for $30 \mathrm{~s}$ was sufficient to inhibit enzyme activity within bone (Lundskog, 1972; Eriksson and Albrektsson, 1983). A temperature of $55^{\circ} \mathrm{C}$ causes marrow necrosis and of $70{ }^{\circ} \mathrm{C}$, macroscopic bone necrosis (Berman et al., 1984). The exposure temperature and duration have been shown to correlate with the depth of penetration of a thermocline within bone. The depth of a $50{ }^{\circ} \mathrm{C}$ isotherm was the same for exposure to $75^{\circ} \mathrm{C}$ for $30 \mathrm{~s}, 80^{\circ} \mathrm{C}$ for $20 \mathrm{~s}$ and $90^{\circ} \mathrm{C}$ for $10 \mathrm{~s}$. The depth of the $50^{\circ} \mathrm{C}$ isotherm increased by $0.4 \mathrm{~mm}$ when the exposure temperature was increased from 75 to $90{ }^{\circ} \mathrm{C}$ for an exposure time of $10 \mathrm{~s}$ (Lundskog, 1972). 


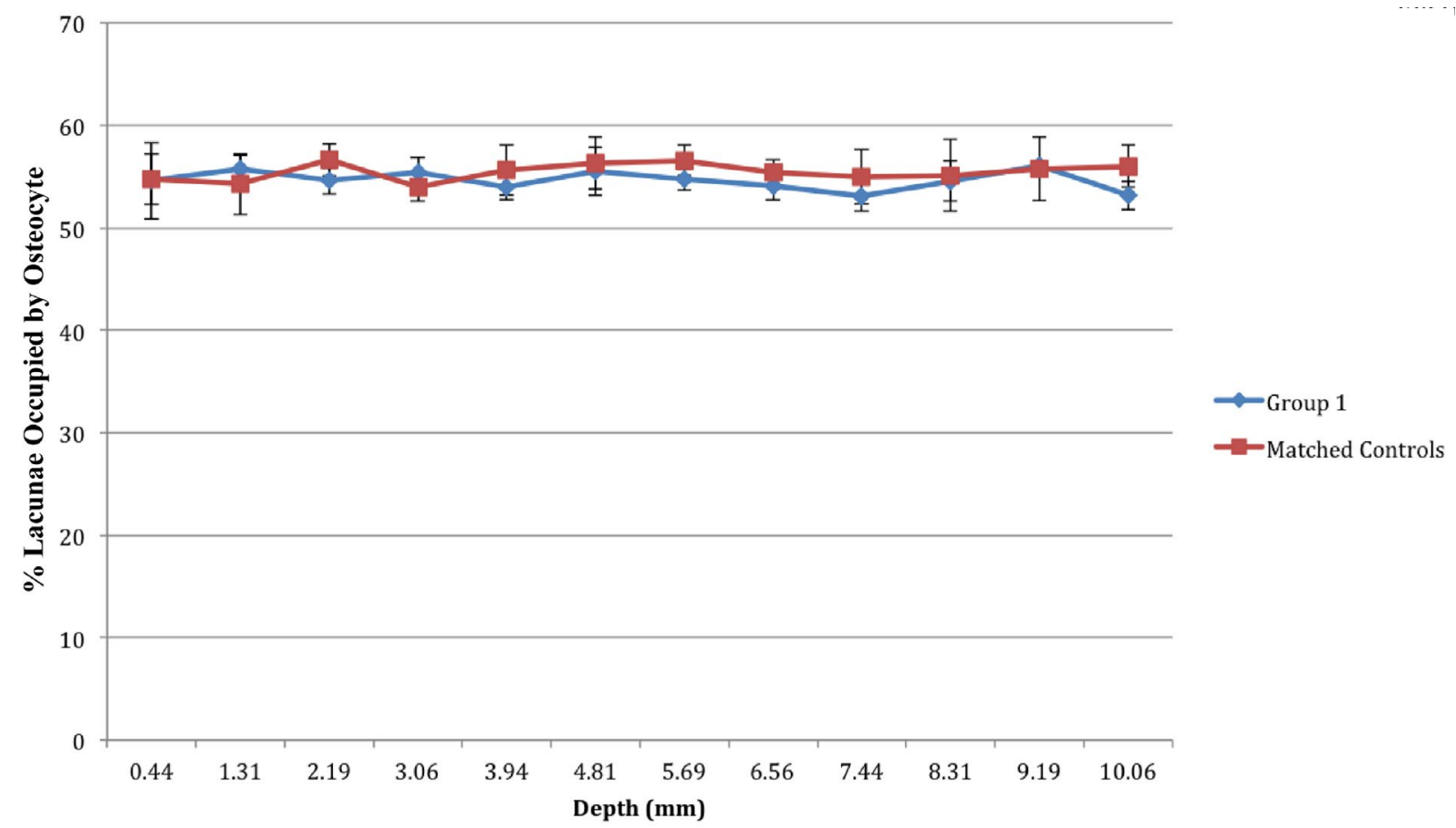

Fig. 10. Observed osteocyte counts (mean $\pm \mathrm{SD}$ ) for the H\&E stain at different depths for group 1 (5 mm mantle) and their matched controls.

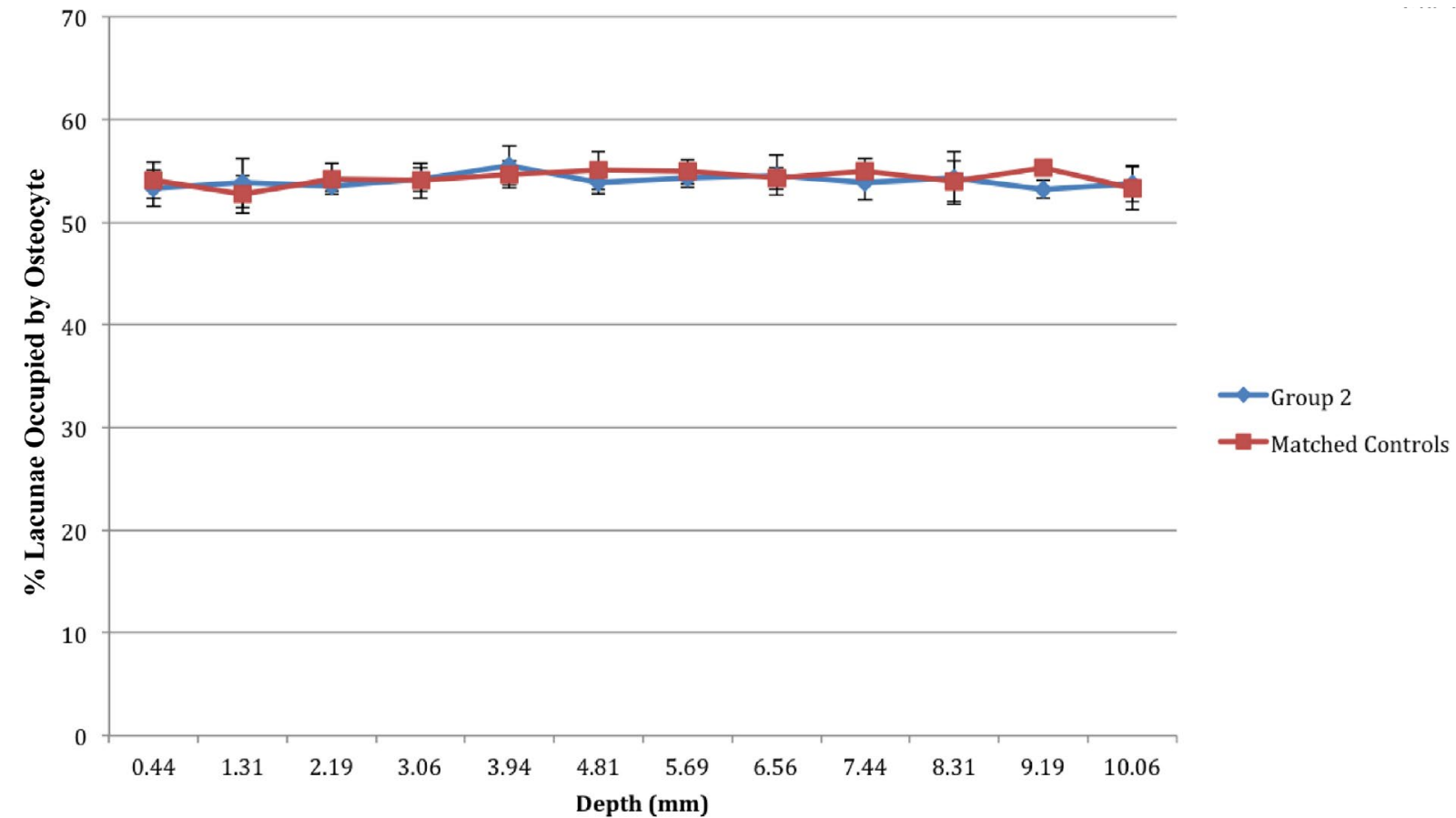

Fig. 11. Observed osteocyte counts (mean $\pm \mathrm{SD}$ ) for the H\&E stain at different depths for group 2 (7 mm mantle) and their matched controls.

Methylmethacrylate monomer has been shown to be toxic, inducing apoptosis in human osteoblasts (Gough and Downes, 2001). Attempts have been made to reduce the potential harm due to PMMA cement such as developing cements with a lower exotherm, lower release of monomer and lower residual monomer content (Kindt-Larsen et al., 1995). Unfortunately, these attempts were unsuccessful in vivo with unacceptably high early revision rates (AbdelKader et al., 2001). The dispersal of monomer relates to the surface area to which it is exposed (Linder et al., 1976) and this was standardised so the difference in osteocyte viability between the groups cannot be explained by this phenomenon. In addition, monomer toxicity compared to surgical and thermal trauma is minimal (Linder, 1977). The amount of monomer released by different brands of cement varies up to fourfold (Santin et al., 2004) and this was standardised by using a single brand and type in this study.

The standardisation of the anatomy of control bone specimens, their harvest and the histological and 
Fig. 12. H\&E stain on bone section of a cortical bone area from group 1 ( $5 \mathrm{~mm}$ cement mantle thickness) at a depth of $0.875 \mathrm{~mm}$ from the surface exposed to curing PMMA cement. The white arrow demonstrates an empty lacuna and the black arrow a lacuna containing a viable osteocyte. A vascular channel is labelled with the letters VC. The exposed surface of bone is closest to the lower edge of the image (scale bar 0-100 $\mu \mathrm{m}$ ).
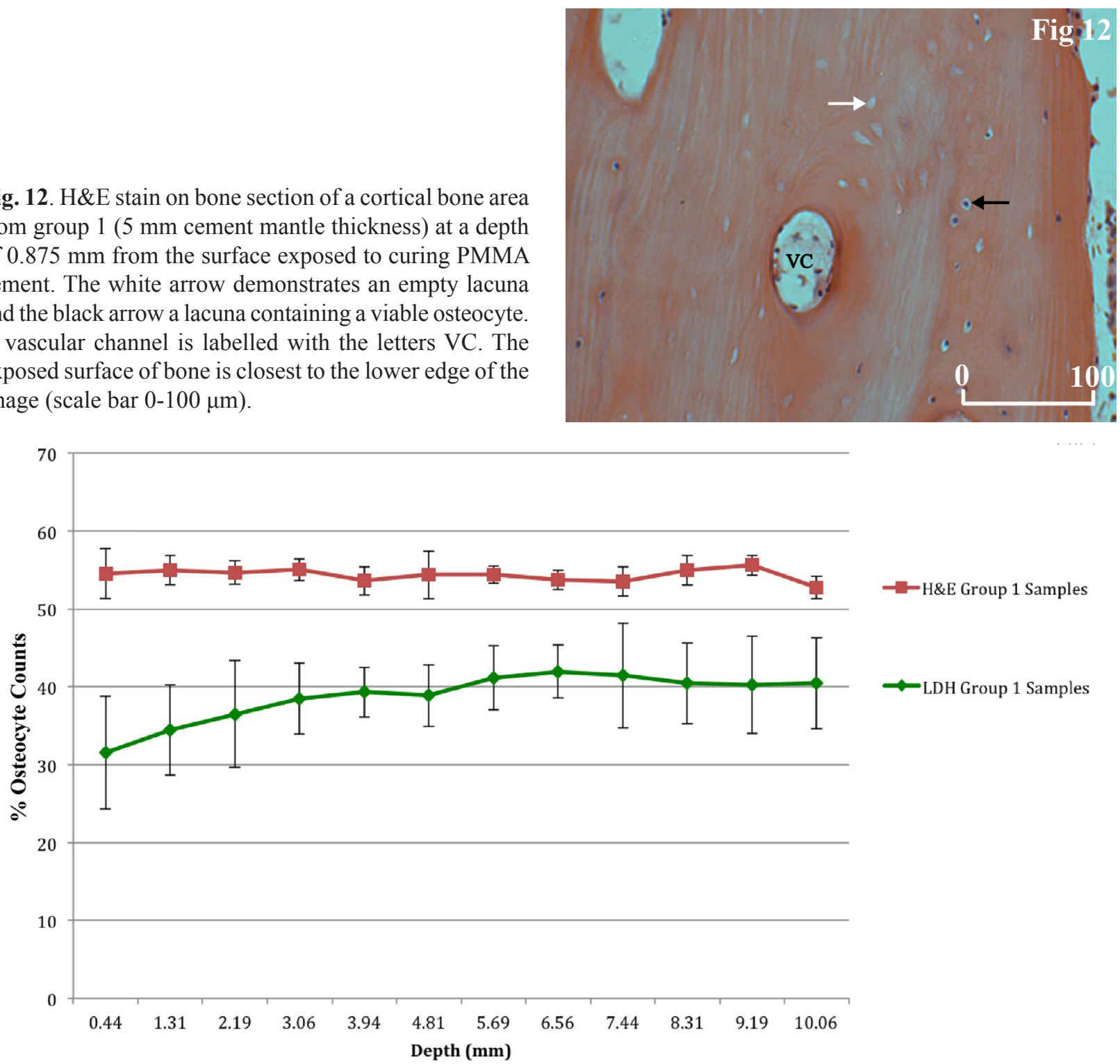

Fig. 13. Comparison of viable osteocyte counts (\%) for Group 1 samples (5 mm PMMA mantle) comparing the results of the LDH assay and H\&E counts, $p$ values all $<0.01$ (range $<0.0001-0.0099$ ).

histochemical techniques used should minimise any differences in cortical and cancellous bone structure, thermal insult of harvesting and baseline osteocyte viability between specimens. Given there was no significant difference observed between the histologically analysed specimens (H\&E) and their controls, we are reassured that there was not a large variation between these specimens harvested at sites in close proximity. The variability between individuals was expected to be larger than the variability between the sample and control specimens. Therefore, the control specimens were felt to be the most appropriate available in this in vivo model. One of the known errors in the assessment of the content of lacunae whether by histological or histochemical analysis is that not all lacunae containing cellular material will be cut such that the content is apparent on analysis. This is one of the limitations of the consideration of a three dimensional structure that is not completely filled by the subject of interest when a two dimensional analysis is performed.
Although this would lead to a lower count than would occur if the true incidence of lacunae content was recorded by an analysis that could account for this, the error is considered consistent across the samples given the large number of lacunae observed between the samples and controls.

Although there was no significant difference in age or gender between the groups, they were not matched for these variables. The lack of any significant difference between the data for the H\&E study and the controls of the LDH assay suggest that this was not a significant factor.

The penetration of cement into the cancellous structure of the samples and controls (Lichtinger and Müller, 1998) was not analysed formally. It was felt that the removal of the PMMA prior to division of the samples for preparation and analysis would have made such an observation meaningless by introducing too much potential variation. It was not possible to leave the PMMA and polyethylene caps intact prior to division and preparation as this would have interfered with the diffusion of the media and 


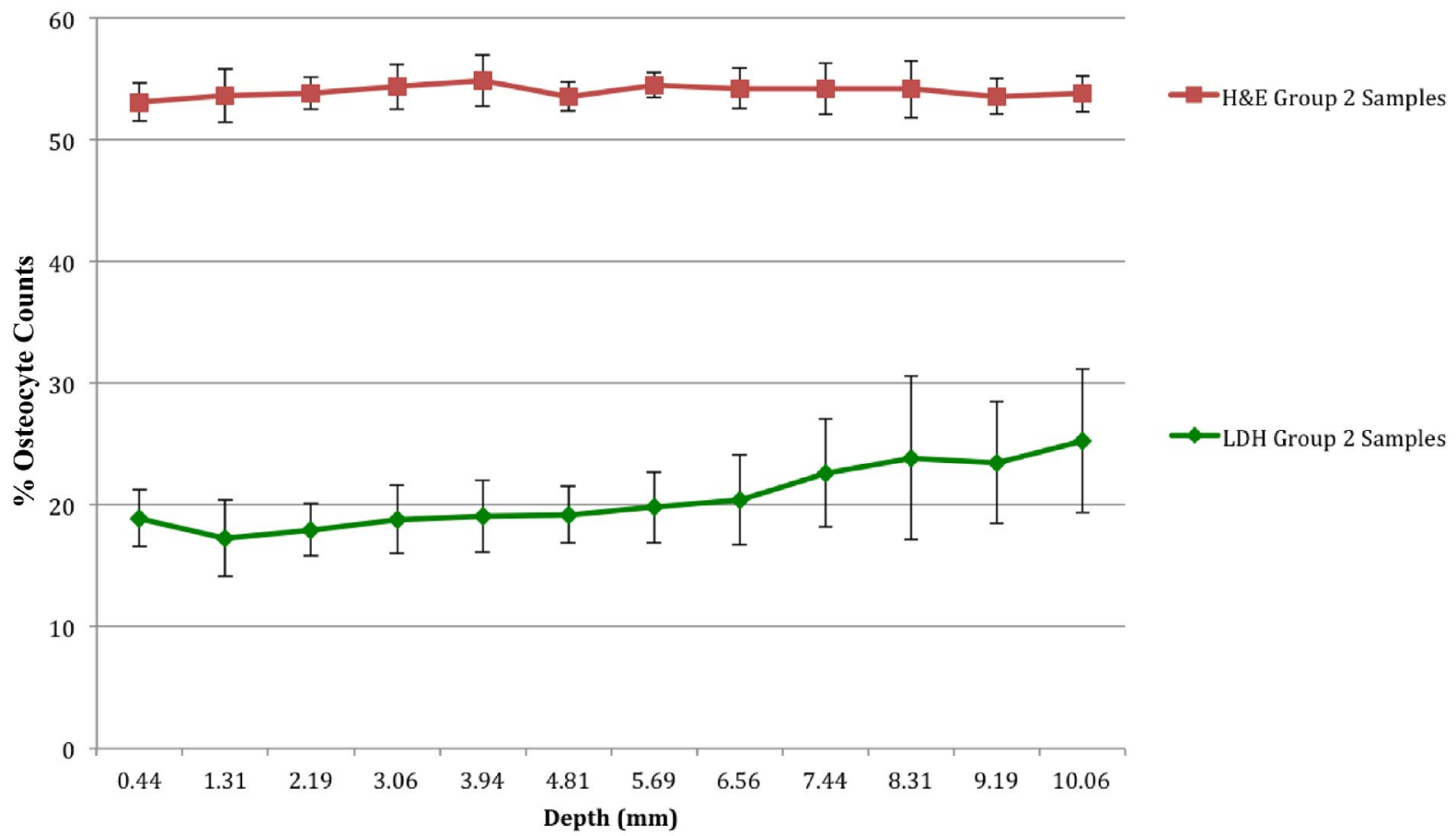

Fig. 14. Comparison of viable osteocyte counts (\%) for Group 2 samples (7 mm PMMA mantle) comparing the results of the LDH assay and H\&E counts, $p$ values all $<0.0001$.

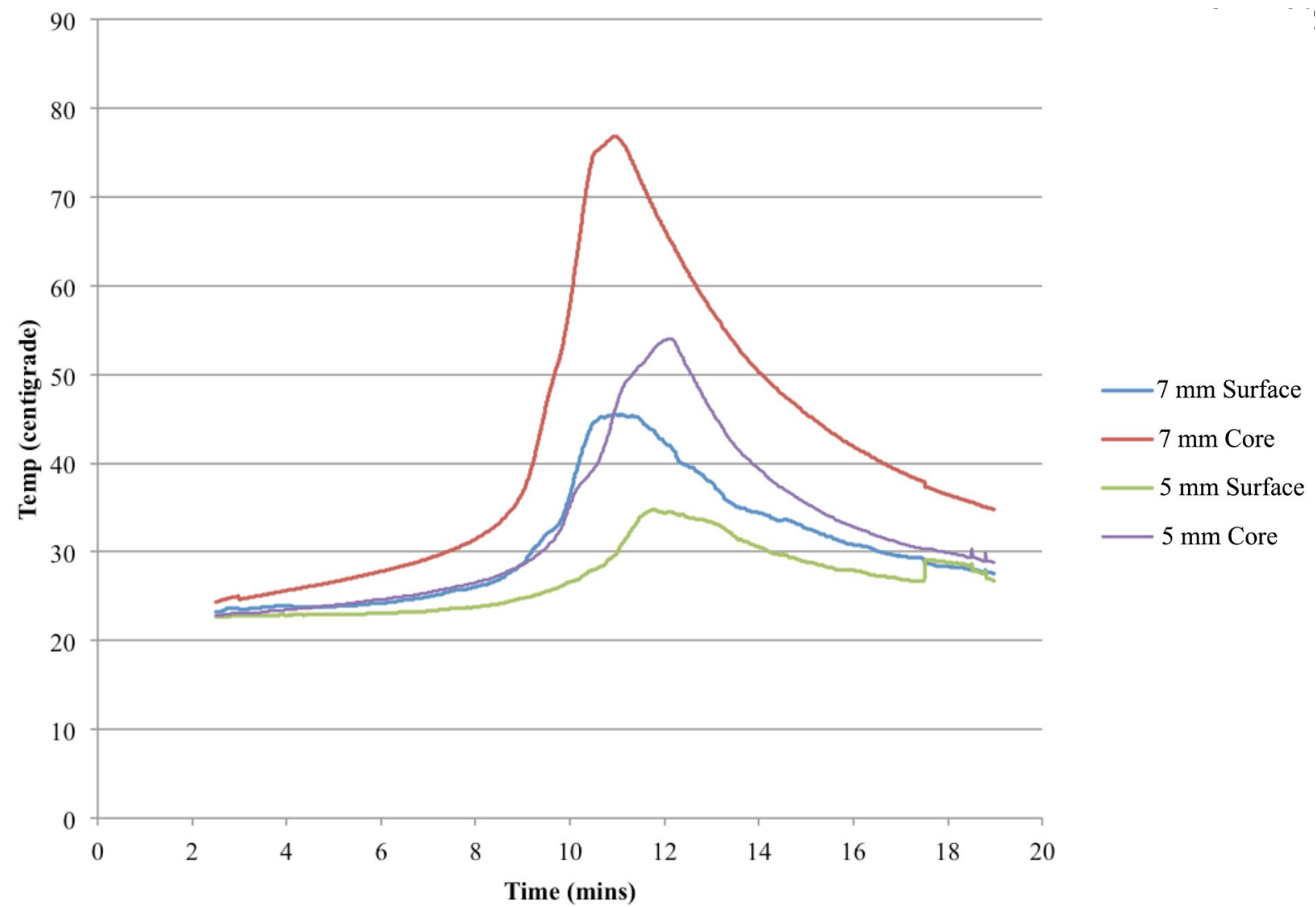

Fig. 15. Mean temperatures ( $n=10$ for each group) during curing measured at surface and core of the $5 \mathrm{~mm}$ or $7 \mathrm{~mm}$ thick cement mantles in the ex vivo femoral necks.

stain into the samples and would have compromised the preparation, particularly in the case of the LDH assay. No gross differences were observed between the specimens in terms of cement penetration.

A number of studies have investigated the ideal thickness of the acetabular cement mantle. Oh suggests that in terms of strain distribution within the cement, the ideal mantle is $3 \mathrm{~mm}$ thick and that the cup should be placed concentrically within the mantle (Oh, 1983). Cement spacers or pods on the outer diameter of the cup can help to achieve this (Nelson et al., 1980) and have been shown to decrease underfilling (less than $2 \mathrm{~mm}$ 
mantle) and overfilling (greater than $8 \mathrm{~mm}$ ) (Lichtinger and Müller, 1998) and to improve concentricity of the cup (Oh et al., 1985; Sandhu et al., 2006). Although the concern emphasised in this study is that a mantle that is too thick may predispose to failure, there is a minimum thickness that needs to be achieved. Finite element analysis has demonstrated decreased fatigue life for mantles of $2 \mathrm{~mm}$ thickness compared to $4 \mathrm{~mm}$ mantles (Coultrup et al., 2009). Laboratory work has supported this with increased mantle stiffness observed in torsion for values less than $1 \mathrm{~mm}$ and no improvement in mechanical properties beyond $4 \mathrm{~mm}$ (Lankester et al., 2007).

The isotherm data collected during this study suggests that human bone in an elderly population undergoing cemented total hip replacement is more sensitive to thermal damage than the young healthy rabbit bone used in these previous studies. Temperatures in excess of $47^{\circ} \mathrm{C}$ were not observed beyond $2 \mathrm{~mm}$ depth in the ex vivo femoral necks but a significant decrease in osteocyte viability was observed to a depth of over $2 \mathrm{~mm}$ in group 1 and over $10 \mathrm{~mm}$ in group 2. The thermal properties of the bone in question are likely to differ from those previously studied. The fact that the femoral neck samples were ex vivo should have exacerbated temperature recordings due to the absent blood flow removing the heat sink effect that occurs in vivo.

Damage to the host bone, on which the fixation of the device is reliant, remains a concern and a potential area for optimisation of materials and technique. Despite this concern, the long-term survivorship of cemented total hip replacement remains very good with a $94 \%$ revision free survival at 10 years (Hailer et al., 2010). This is superior to the results of uncemented total hip replacement, predominantly due to the lower survival rate of uncemented acetabular components, which although exposed to the same surgical trauma, are not exposed to the thermal insult or monomer leakage that cemented acetabular components are. This study demonstrates that bone viability assays, such as the LDH assay are useful in the observation of thermal trauma and that an increased cement mantle thickness is correlated with increased damage to the host bone as measured by osteocyte viability. H\&E staining does not provide the same information as the LDH assay in this study, as the H\&E stain remains positive for cellular material in osteocytes that have undergone necrosis due to thermal or other insults. It is only after resorption of this cellular material that the stain becomes negative, a process that is dependent upon autolysis of the cells and an intact blood supply. What is not clear is if there is a threshold at which this effect would become clinically significant. We believe that such radiolucencies may develop following the thermal insult and decreased osteocyte counts observed in this study, however investigating this link was beyond the scope of this paper. The correlation between radiolucencies around the cemented acetabular component and subsequent loosening is well established (García-Cimbrelo et al., 1997; Ritter et al., 1999). The latter of these two studies investigated the effect of cement mantle thickness but found no correlation with loosening. Radiolucencies in the early post-operative period may be observed due to the inadequate preparation of the host bone or inadequate penetration of the cement into the host bone and hence be present from the time of operation or they may appear after surgery due to the resorption of bone at the interface. Variations in examinations performed, such as projection in plain radiography when analysing a hemispherical interface make this a difficult area to study as it is unclear exactly when a radiolucency first appeared and hence its cause.

Information gained from retrieval analysis of cemented acetabular components that have been in situ for medium to long-term follow up are important in allowing us to understand the possible consequence of early osteonecrosis induced at the time of implantation. Charnley reported the results of 26 post-mortem specimens, which demonstrated a 0.5 to $1.5 \mathrm{~mm}$ thick fibrous membrane interposed between the bone and bone cement in all specimens (Charnley, 1979). Malcolm reported the results of 78 cemented Charnley acetabular components, which had been in situ for up to 20 years and demonstrated a thick fibrous layer interposed between the bone and bone cement in all cases (Malcolm, 1993). He observed the presence of a variable number of particles within the layer. Fornasier et al. studied 14 post mortem specimens at a mean time of 4.7 years from implantation in patients that were asymptomatic at the time of death (Fornasier et al., 1991). The density of histiocytes within the observed membranes correlated with the thickness of the membrane, the density of the polyethylene particles within the membrane and the period of time in situ. It was observed that the fibrohistiocytic membrane observed in all the acetabular samples was similar to that described in loose implants. Schmalzried et al. (1992) performed post mortem examination of 14 retrieved acetabular components; they observed that late loosening was mediated by progressive resorption of bone immediately adjacent to the cement mantle. The process began at the margin of the joint space and stability of the implant was determined by the degree of resorption. The soft tissue layer was universally present and was thickest at the periphery. It is known that the extent of radiological demarcation around cemented acetabular components is correlated with the risk of the component being loose and is a prognostic sign of failure (Hodgkinson et al., 1988).

Potential confounding factors in the experimental model include the toxicity of polymethylmethacrylate monomer to bone, the thermal insult from harvest of and preparation of the specimen, the difference in the cancellous and cortical structure of the bone in the femoral neck (specimens) and head (control), the difference in the proportion of viable osteocytes in the neck and head and the difference in penetration of cement into the cancellous bone during preparation.

This study demonstrates that the effect of the thermal insult delivered by curing PMMA on osteocyte viability in a population undergoing total hip replacement is of greater magnitude than previously thought. It has also been demonstrated that previous studies that relied on histological rather than histochemical methods may have underestimated this effect. We would suggest that work to correlate mantle thickness to the formation and progression of radiolucencies and subsequent failure whilst controlling for mantle thickness eccentricity would be useful to 
determine if this effect is clinically significant. We also propose that simple techniques such as the application of cooled saline lavage may ameliorate the effect that we have observed.

\section{Conclusion}

Our findings suggest that thick cement mantles of $5 \mathrm{~mm}$ should be avoided due to the degree of thermal damage induced. A mantle of $2.5 \mathrm{~mm}$ would appear to give the optimum balance between mechanical properties of the mantle and reducing the risk of thermal damage to the host bone.

\section{Acknowledgements}

The authors would like to formally acknowledge the support of DePuy International Ltd. (Leeds, UK), Stryker UK (Newport, UK), Heraeus Medical GmbH (Wehrheim, Germany), the Royal College of Surgeons of England and the British Hip Society. DePuy International provided a clinical research grant (amount less than $£ 10,000$ ) in support of the materials costs of the project. Stryker UK and Heraeus Medical GmbH supplied consumables used during the conduct of the project. The first author was awarded the McMinn Scholarship by the British Hip Society and a Research Fellowship by the Royal College of Surgeons of England and occupied those positions during the course of the study. The authors also wish to express their gratitude to Dr John Tarlton, Senior Research Fellow, Veterinary School, University of Bristol for his invaluable assistance and support in the preparation of specimens and to Mr James Heal, Consultant Orthopaedic Surgeon for his assistance in the collection of intraoperative specimens.

\section{References}

Abdel-Kader KF, Allcock S, Walker DI, Chaudhry SB (2001) Boneloc bone-cement: experience in hip arthroplasty during a 3-year period. J Arthroplasty 16: 811-819.

Askew MJ, Steege JW, Lewis JL, Ranieri JR, LL WR (1983) Effect of cement pressure and bone strength on polymethylmethacrylate fixation. J Orthop Res 1: 412-420.

Bannister G (2003) Primary total hip replacement. Surgeon 1: 332-341.

Berman AT, Reid JS, Yanicko DR, Sih GC, Zimmerman MR (1984) Thermally induced bone necrosis in rabbits. Relation to implant failure in humans. Clin Orthop Relat Res 186: 284-292.

Berry DJ, Bozic KJ (2010) Current practice patterns in primary hip and knee arthroplasty among members of the American Association of Hip and Knee Surgeons. J Arthroplasty 25: 2-4.

Chang RW, Pellisier JM, Hazen GB (1996) A costeffectiveness analysis of total hip arthroplasty for osteoarthritis of the hip. JAMA 275: 858-865.

Charnley J (1960) Anchorage of the femoral head prosthesis to the shaft of the femur. J Bone Joint Surg Br 42: 28-30.
Charnley J (1979) Low friction arthroplasty of the hip: Theory and practice. Springer-Verlag, New York. pp 25-40.

Coultrup OJ, Hunt C, Wroblewski BM, Taylor M (2009) Computational assessment of the effect of polyethylene wear rate, mantle thickness, and porosity on the mechanical failure of the acetabular cement mantle. J Orthop Res 28: 565-570.

DiPisa JA, Sih GS, Berman AT (1976) The temperature problem at the bone-acrylic cement interface of the total hip replacement. Clin Orthop Relat Res 121: 95-98.

Eriksson AR, Albrektsson T (1983) Temperature threshold levels for heat-induced bone tissue injury: a vital-microscopic study in the rabbit. J Prosthet Dent 50: 101-107.

Eriksson AR, Albrektsson T, Magnusson B (1984) Assessment of bone viability after heat trauma. A histological, histochemical and vital microscopic study in the rabbit. Scand J Plast Reconstr Surg 18: 261-268.

Flivik G (2005) Fixation of the cemented acetabular component in hip arthroplasty. Acta Orthop Suppl 76: 3-30.

Fornasier V, Wright J, Seligman J (1991) The histomorphologic and morphometric study of asymptomatic hip arthroplasty. A postmortem study. Clin Orthop Relat Res 271: 272-282.

García-Cimbrelo E, Diez-Vazquez V, Madero R, Munuera L (1997) Progression of radiolucent lines adjacent to the acetabular component and factors influencing migration after Charnley low-friction total hip arthroplasty. J Bone Joint Surg Am 79: 1373-1380.

Goldberg VM, Buckwalter J, Halpin M, Jiranek W, Mihalko W, Pinzur M, Rohan B, Vail T, Walker P, Windsor R, Wright T (2011) Recommendations of the OARSI FDA Osteoarthritis Devices Working Group. Osteoarthritis Cartilage 19: 509-514.

Gough JE, Downes S (2001) Osteoblast cell death on methacrylate polymers involves apoptosis. J Biomed Mater Res 57: 497-505.

Hailer NP, Garellick G, Kärrholm J (2010) Uncemented and cemented primary total hip arthroplasty in the Swedish Hip Arthroplasty Register. Acta Orthop 81: 34-41.

Hodgkinson JP, Shelley P, Wroblewski BM (1988) The correlation between the roentgenographic appearance and operative findings at the bone-cement junction of the socket in Charnley low friction arthroplasties. Clin Orthop Relat Res 228: 105-109.

Humphreys S, Spencer JD, Tighe JR, Cumming RR (1989) The femoral head in osteonecrosis. A quantitative study of osteocyte population. J Bone Joint Surg Br 71: 205-208.

Kindt-Larsen T, Smith DB, Jensen JS (1995) Innovations in acrylic bone cement and application equipment. J App Biomater 6: 75-83.

Kühn KD (2000) Bone cements: up-to-date comparison of physical and chemical properties of commercial materials 1st ed. Springer-Verlag New York,: Chapter 1.

Lankester BJA, Sabri O, Gheduzzi S, Stoney JD, Miles AW, Bannister GC (2007) In vitro pressurization of the acetabular cement mantle. J Arthroplasty 22: 738-744.

Leeson MC, Lippitt SB (1993) Thermal aspects of the use of polymethylmethacrylate in large metaphyseal 
defects in bone. A clinical review and laboratory study. Clin Orthop Relat Res 295: 239-245.

Lichtinger TK, Müller RT (1998) Improvement of the cement mantle of the acetabular component with bone cement spacers. A retrospective analysis of 200 cemented cups. Arch Orthop Trauma Surg 118: 75-77.

Linder L (1977) Reaction of bone to the acute chemical trauma of bone cement. J Bone Joint Surg Am 59: 82-87.

Linder LG, Harthon L, Kullberg L (1976) Monomer leakage from polymerizing acrylic bone cement. An in vitro study on the influence of speed and duration of mixing, cement volume and surface area. Clin Orthop Relat Res 119: $242-249$.

Lundskog J (1972) Heat and bone tissue. An experimental investigation of the thermal properties of bone and threshold levels for thermal injury. Scand J Plast Reconstr Surg 9: 1-80.

Mahomed N, Gandhi R, Daltroy L, Katz JN (2011) The self-administered patient satisfaction scale for primary hip and knee arthroplasty. Arthritis 2011: 1-6.

Malcolm AJ (1993) Cemented and HydroxyapatiteCoated hip implants: An autopsy retrieval study. In: Biological, Material, and Mechanical Considerations of Joint Replacement. Raven Press, New York, pp 39-50.

Mburu G, Aspden RM, Hutchison JD (1999) Optimizing the configuration of cement keyholes for acetabular fixation in total hip replacement using Taguchi experimental design. Proc Inst Mech Eng H 213: 485-492.

Moritz AR, Henriques FC (1947) Studies of thermal injury II. Am J Path. 23: 695-720.

Nelson CL, Haynes DW, Weber MJ, McLeod PC (1980) Device and method for controlling cement thickness. Clin Orthop Relat Res 151: 160-164.

NJR Steering Commitee (2011) National Joint Registry for England and Wales: 8th Annual Report. Hemel Hempstead, UK.

Oh I (1983) A comprehensive analysis of the factors affecting acetabular cup fixation and design in total hip replacement arthroplasty: a series of experimental and clinical studies. Hip 1983: 129-177.

Oh I, Sander TW, Treharne RW (1985) Total hip acetabular cup flange design and its effect on cement fixation. Clin Orthop Relat Res 195: 304-309.

Quarini GL, Learmonth ID, Gheduzzi S (2006) Numerical predictions of the thermal behaviour and resultant effects of grouting cements while setting prosthetic components in bone. Proc Inst Mech Eng $\mathrm{H}$ 220: 625-634.

Räsänen P, Paavolainen P, Sintonen H, Koivisto A-M, Blom M, Ryynänen O-P, Roine RP (2007) Effectiveness of hip or knee replacement surgery in terms of qualityadjusted life years and costs. Acta Orthop 78: 108-115.

Revie I, Wallace M, Orr J (1994) The effect of PMMA on thermal bone necrosis around acetabular sockets. Proc Inst Mech Eng H 208: 45-51.

Ritter MA, Zhou H, Keating CM, Keating EM, Faris PM, Meding JB, Berend ME (1999) Radiological factors influencing femoral and acetabular failure in cemented Charnley total hip arthroplasties. J Bone Joint Surg Br 81: 982-986.
Sandhu HS, Martin WN, Bishay M, Pozo JL (2006) Acetabular cement mantles and component position. J Arthroplasty 21: 841-845.

Santin M, Motta A, Borzachiello A, Nicolais L, Ambrosio L (2004) Effect of PMMA cement radical polymerisation on the inflammatory response. J Mater Sci Mater Med 15: 1175-1180.

Schmalzried TP, Kwong LM, Jasty M, Sedlacek RC, Haire TC, O'Connor DO, Bragdon CR, Kabo JM, Malcolm AJ, Harris WH (1992) The mechanism of loosening of cemented acetabular components in total hip arthroplasty. Analysis of specimens retrieved at autopsy. Clin Orthop Relat Res 274: 60-78.

Sih GC, Connelly GM, Berman AT (1980) The effect of thickness and pressure on the curing of PMMA bone cement for the total hip joint replacement. J Biomech 13: 347-352.

Slooff TJ (1971) The influence of acrylic cement: An experimental study. Acta Orthop 42: 465-481.

Stoddart MJ, Furlong PI, Simpson A, Davies CM, Richards RG (2006) A comparison of non-radioactive methods for assessing viability in ex vivo cultured cancellous bone: technical note. Eur Cell Mater 12: 16-25.

Toksvig-Larsen S, Franzen H, Ryd L (1991) Cement interface temperature in hip arthroplasty. Acta Orthop Scand 62: 102-105.

Wong SYP, Dunstan CR, Evans RA, Hills E (1982) The determination of bone viability: a histochemical method for identification of lactate dehydrogenase activity in osteocytes in fresh calcified and decalcified sections of human bone. Pathology 14: 439-442.

\section{Discussion with Reviewers}

H. Plenk: I do not understand the logic of mentioning a lack of differences between H\&E data and only the control data for the LDH-assay.

Authors: As we feel that the $H \& E$ analysis does not capture osteocyte death secondary to the thermal insult delivered by the curing PMMA cement in this study, the data from the $\mathrm{H} \& \mathrm{E}$ arm is comparable to the controls in the LDH assay arm. If there had been a significant error introduced by the fact that the patients were not truly matched for age and gender (only established to not be significantly different in this respect), we would have expected to observe a difference between the data from the H\&E specimens and controls (between which there were no significant differences) and the LDH controls.

H. Plenk: Concerning Fig.2, when speaking of the in vivo model, then also for this illustration one intra-operative photograph could be used. I cannot imagine that the procedure was never documented in this study. A not too bloody picture would be better and than this macerated proximal femur, and still informative!

Authors: No intraoperative photographs of the in vivo model are available. In the jurisdiction in which the study was conducted, separate consent, beyond that for participation in the study, would have been required as 
intraoperative photography was not part of the our research protocol. We were and remain very aware of the burden of participation on our patients and did not feel that such a photograph would add additional information to the representative figure. Given the nature of the surgery and the materials used in the study, the contrast of an intraoperative photograph would have led to a less clear image than that provided.

Reviewer II: If the paper is considered as an analytic scientific model, out of which should come a greater understanding of how bone dissipates and physiologically responds to excess heat, the work fails because the authors do not explain how their finite element analysis relates to the thermodynamics of cancellous bone conductivity. There are nonlinearities hidden by the approximations for setting up boundary conditions that allow the analysis to produce its predictions. The result may be acceptable engineering, but it is not science. However, there is also the empirical engineering need for a technique to evaluate thermal osteonecrosis under the real life conditions of human hip surgery. By this standard the work makes a useful addition to improving assessment of outcomes. Please comment. Authors: We indeed wished to determine the extent of thermal osteonecrosis under the in vivo conditions of a population undergoing cemented total hip arthroplasty. We feel that this has not previously been determined in an in vivo model representative of the population undergoing the procedure, which was surprising given the popularity of the procedure. We did not go into further detail regarding the finite element model in this manuscript as this was outside the scope of the work presented. In this manuscript, we wished to focus on the extent of the thermal osteonecrosis induced by the different cement mantel thicknesses, and how this relates to the performance of the surgery and optimisation of the surgical technique in real life. We recognise that the finite element model analysis can only ever be an approximation of the complex factors involved and interactions between these factors. It is however a widely accepted method for the approximation of such conditions in complex models.

Reviewer III: Studies by Willert as early as the late 1970s described time-dependent changes at the bone/cement interface. Of note: "The cells of the bone marrow and of the bone surrounding the methylmethacrylate implant become necrotic for a distance of $3 \mathrm{~mm}$. In the course of the subsequent repair of tissue damage ... the necrotic zone is organised, proceeding from the intact surrounding tissue". I will admit he made those observations from a mixed batch of specimens, not from any well-designed experimental study, but that fundamental process is reasonable, and the authors of this manuscript do not disagree that "long term remodeling occurs".
Authors: We agree that long term remodelling occurs around cemented total hip arthroplasties and indeed, all implants. We do feel that achieving sufficient stability is essential to ensuring the success of cemented arthroplasty and that if the degree of thermally induced osteonecrosis is too great that this stability will be lost and cannot be compensated for by ingrowth from intact surrounding tissue. It has been well demonstrated in the context of uncemented implants that excessive motion prevents bone ingrowth (Cameron et al., 1973; Curtis et al., 1992, additional references). It has also been shown that cemented acetabular components do not osseointegrate in the manner suggested (DeLee and Charnley, 1976, additional reference; Schmalzried et al., 1992, text reference).

Reviewer III: I still maintain that "everyone knows" the exotherm of PMMA can cause bone necrosis, and that the extent of necrosis is largely dependent on the volume of cement. I readily acknowledge that more information about the bone/cement interface in successful and failed cemented acetabular components is desirable, but my point is that the many limitations inherent in the in vivo femoral model described in this manuscript preclude the study from providing very much additional useful information beyond what is already known.

Authors: We respectfully disagree with this opinion. Whilst it is known that the curing of PMMA is an exothermic reaction and animal models have demonstrated bone necrosis due to this insult, we maintain that although this information provides a useful background, it does not adequately reflect the situation in elderly human bone that is relevant to a population undergoing cemented arthroplasty with a cement mantle rather than bolus. Evidence relevant to this was not previously available. As is made clear in the discussion, we are aware of and acknowledge the limitations of our model but it is the best evidence currently available relevant to the effect the curing of the cement mantle on elderly human bone in vivo undergoing cemented total hip arthroplasty.

\section{Additional References}

Cameron HU, Pilliar RM, Macnab I (1973) The effect of movement on the bonding of porous metal to bone. $\mathrm{J}$ Biomed Mater Res 7: 301-11.

Curtis MJ, Jinnah RH, Wilson VD, Hungerford DS (1992) The initial stability of uncemented acetabular components. J Bone Joint Surg Br 74: 372-376.

DeLee JG, Charnley J (1976) Radiological demarcation of cemented sockets in total hip replacement. Clin Orthop Relat Res 121: 20-32. 